business schemes (for example, methods of office management); (iii) commercial, financial and propaganda schemes; (iv) treatment of human beings; (v) designs or arrangements in which the novelty resides solely in appeal to the eye, (vi) designs or arrangements which serve only to convey information and in which the novelty resides solely in the information conveyed.

The Group recommends that adequate steps should be taken to enlighten agricultural interests as to the changes in the United Kingdom law which are contemplated and to explain the reasons for these changes.

The Group points out that the unification Convention does not completely solve the problem of how to resolve conflict with prior unpublished applications. Article 6 of the Convention broadly requires that parties of the Convention shall not allow double patenting. The present statutory provisions in the United Kingdom rest basically on the principle that double patenting is to be avoided, but the interpretation given to these provisions in recent years has produced serious difficulties. The Group agreed generally that a straightening out of United Kingdom law is necessary to bring some real sense into this subject quite apart from the requirements of the Convention. Generally, the Group is also agreed that a later patent should not be granted if it purports to prevent the working of the invention as claimed in an earlier patent in any manner in which a competent person would normally work it. Some suggested forms of wording for this 'prior claim' proposal are appended to the report. Nevertheless, the Group concludes that there should be no requirement that a patent granted on the earlier application should be granted, or valid if granted.

\title{
THE FUTURE OF NUCLEAR POWER
}

\begin{abstract}
$\mathrm{T}_{\mathrm{H}}^{\mathrm{H}}$ HE John Macrossen Lecture was given by Sir John Cockcroft in the same year as the third International Conference on Atomic Energy was held at Geneva. The Lecture is a very brief staternent of the prospects of the economic development of nuclear power at that date, a subject very fully dealt with at Geneva. The capital costs per $\mathrm{kW}$ of electricity generated by the stations built by industry for the Central Electricity Generating Board will almost have halved in the 6 years between the completion of the 275-MW Berkeley station and the 1,180-MW Wylfa nuclear station, each of them containing two reactors. The fall is due in large part to the increased size of the unit; fuel costs have also fallen, but the overall cost of power by any calculation is still higher than that from coal-fired stations of the same dates.

The advanced type of gas-cooled reactor was expected in 1964 to cost less than a coal station of the same date, and within a year of the delivery of this Lecture the firm tender prices for the Dungeness $B$ nuclear station showed that this was, in fact, the case, provided the station is built at the tender price.
\end{abstract}

In the United States similar dramatic falls in costs have been experienced with their water moderated reactors; and Canada's heavy-water reactor is expected to have very low fuel costs, although it will have a high capital cost.

These types of reactors, by the end of the century, would be using 100,000 tons of uranium per annum, on reasonable assumptions as to the rate of development of nuclear stations. To avoid a rise in the cost of raw materials, more of the uranium-238 must be used; the experimental fast reactor at Dounreay has operated well enough now to justify a design study for a 1,000-MW reactor to be ready for the late 1970's; this might herald a new generation of stations to use up the plutonium from the slow-neutron reactors and the fast reactor might breed $\mathbf{1 . 5}$ times the amount of fuel it uses.

Fusion reactions still remain as a possibility and as a hope for the future; stability of the confined plasma at low pressures has been achieved but not at high densities. It would be idle at present to predict whether these schemes will be successful.

T. E. Allimone

\section{NUMERICAL METHODS IN SUBSONIC FLUID DYNAMICS}

A

SYMPOSIUM on "Numerical Methods in Subsonic Fluid Dynamics" was held at the National Physical Laboratory during September 27-29, 1965, the local organization being shared jointly by the Aerodynamics and Mathematics Divisions. More than one hundred and thirty visitors from industry, universities, technical colleges and Government establishments, including several from Europe and the United States, participated in the programme, which was divided into four sessions, each consisting of two general survey lectures followed by three parallel discussion groups $A, B$ and $C$. The subjects of the discussion groups were arranged so that $A$ was a follow-up of the general lectures of the session, $B$ was an independent subject introduced by a scheduled talk, and $C$ was a more specialized subject determined by popular demand from the participants themselves.

The original initiative for the meeting came from the Aeronautical Research Council, which had some two years ago anticipated the need for a comprehensive examination of the role of the computer in fluid dynami cs by setting up a Computer Panel. Quite early on, it became clear to the Panel that the full potentialities of the modern 'third generation' computer were not being adequately explored; consequently this symposium was arranged with the objects of elucidating some of the problems involved in the application of computers to fluid motions, and of stimulat- ing interest in the exploration of new approaches to the subject which might be brought within the realms of possibility by the latest computing facilities.

The participants were welcomed by Dr. R. C. Pankhurst, representing the Acting Director of the Laboratory. Prof. B. Thwaites of Southampton University, chairman of the Computer Panel, then gave an introductory talk, in which he outlined the main problems facing the symposium. He suggested that scientists now needed to re-examine their motivations in research-were they interested mainly in mathematical analysis (which, in fluid dynamies, is very difficult) or in numerically expressed results? The answer might be different for the designer and for the 'pure' scientist. In either case, however, it was necessary to take into account the possibility of currently outstanding problems being solved, even within the next ten or twenty years, at tho touch of a button; for this should surely influence the directions which work will take in the intervening period. Thus he emphasized the importance of directing tho discussions towards what will be done in the future.

This was followed by a talk on "The Relevance of Numerical Analysis" by Prof. L. Fox of the University of Oxford. He concerned himself mainly with the finitedifference solution of the relevant types of partial differential equation, paying particular attention to the solu- 
tion by iterative methods of the associated difference equations. He also discussed the problem of truncation error, in particular the treatment of singularities, but emphasized the outstanding gap remaining between the practical problems one wanted to solve and the problems for which rigorous error estimates could be given. Questions of stability arise with initial-value problems, and these he discussed with reference to parabolic equations. Among other topics mentioned were the effect of nonlinearities and problems with free boundaries.

The participants then split up into the three parallel discussion groups, $A, B$ and $C$. In this session, group $A$ was on "Numerical Analysis" and was chaired by Dr. E. T. Goodwin (National Physical Laboratory); the discussion ranged over a wide variety of questions raised by Prof. Fox's talk. Group $B$ was concerned with "Meteorological Forecasting by Computer" and was chaired by Prof. P. A. Sheppard (Imperial College of Science and Technology); it was introduced by Mr. E. Knighting of the Meteorological Office. Mr. Knighting outlined the three main computing tasks involved: selection of reliable data from those received from the international recording stations, conversion of this for use on a regular square grid, and, finally, integration of the relevant equations. With regard to the latter he discussed methods of integrating simple vorticity equations with the emphasis on simplicity and time-saving since forecasting must be carried out in real time. A lively and worth-while discussion followed.

In the other parallel discussion group $(C)$ a relatively small number had assembled to discuss "Magnetohydrodynamics" under the chairmanship of Mr. D. S. Butler (University of Strathclyde). Several problems were mentioned that clearly needed the use of a large computer, but it appeared that in some cases these were being tackled without sufficient consideration of the physical concepts involved; in particular, problems were being tackled which seemed to be far too complex to offer any hope for a successful conclusion, and it was remarked that the computer seemed to be inducing people to run away from reality. A lively discussion followed on how com. puters could best be used, and the view that it would be profitable at this stage to try to compute simple 'component flows' first was widely supported.

The morning session of the following day began with a lecture by Mr. A. M. O. Smith of Douglas Aircraft on "Integral Equation Methods for Potential Problems", in which he demonstrated that, with the advent of large computers, these methods, based on source distributions over the surface of the body, had become a practical means of computation for general non-lifting threedimensional problems. The numerical procedure was basically quite simple and consisted in reducing the problem to an algebraic one by dividing the body up into a large number of small elements and assuming the source density constant over each element. The most complicated problem attempted to date was the determination of the flow over a swept wing having two jet-engine nacelles complete with pylons and internal ducts. Though this problem was really beyond the capacity of the present computing equipment, the calculations and test data were in better than merely qualitative agreement.

Mr. J. A. Bagley of the Royal Aircraft Establishment followed with a survey lecture on "Subsonic Wing Design". $\mathrm{He}$ traced the development of the traditional methods of wing design and discussed the difficulties which have to be faced in improving them. He made it abundantly clear that it will be quite insufficient merely to improve methods of calculating the inviscid incompressible flow, but pointed out that even for the much simpler twodimensional case the problem of calculating the viscous compressible flow seemed to be some way from being solved.

In the following discussion groups, $A$ was concerned with "Inviscid Flow" (chairman: Prof. G. N. Ward,
University of Sussex), $B$ with "Programming Languages and Programme Interchange" (chairman: Prof. S. Gill, Imperial College), and $C$ with "Hydrodynamic Stability" (chairman: Mr. M. Gaster, National Physical Laboratory). In the $A$ group the topics discussed were centred around wing theory; in particular there were discussions on recent methods for lifting surfaces, and on the non-convergence of the circulation when the displacement effect of the boundary-layer is taken into account. Mr. P. M. Woodward of the Royal Radar Establishment introduced discussion $B$ with a brief historical review of programming and an analysis of the role of the specialist systemsprogrammer. He emphasized the need for mathematicians and numerical analysts to become literate in Algol. A lively discussion ensued which tended to underline the difficulties of thinking in terms of using a nebulous machine to which one might have access in the future when results were needed to-morrow. In group $C$ the main topic discussed was the application of modern computer techniques for eigenvalue problems to linear stability theory, particularly in regard to boundary-layer stability.

The first half of the afternoon session consisted of a double lecture on "Boundary-layer Problems" shared by Prof. K. Stewartson of University College, London, and Dr. K. W. Mangler of the Royal Aircraft Establishment. This was confined solely to laminar boundarylayers, for which a determinate system of equations exists. Prof. Stewartson gave detailed consideration to the nature of the initial-/boundary-value problems which arise for these equations and to the simpler numerical techniques for their solution. He observed that the first real difficulty arises near separation, where in general the wall friction vanishes with a singularity, and mentioned techniques which could deal satisfactorily with this. He emphasized the importance of setting oneself a well-posed problem for which existence or uniqueness could be proved, and, looking to the future, briefly discussed this question with regard to the treatment of backflow on the basis of the boundary-layer equations. Dr. Mangler carried the story further, dealing with the extra complications encountered with compressible flow and quasi-three-dimensional flow on a conical surface. He also described in greater detail the various methods that had been programmed for specific problems and discussed a technique for adjusting the external pressure distribution so as to obtain a regular solution at separation.

The subjects for the discussion groups after tea were as follows: $A$ - "Boundary-layer Problems" (chairman, Prof. L. Howarth, University of Bristol; $B$-"Freeboundary Problems" (chairman, Prof. M. B. Glauert, University of East Anglia); $C$-"Numerical Analysis" (chairman, Mr. C. W. Clenshaw, National Physical Laboratory). In group $A$ Mr. G. S. Ruetz (Northrop Aircraft) gave an account of his finite-difference method for solving the three-dimensional boundary-layer equations. This was followed by a general discussion of points arising out of the previous lecture. Mr. J. H. B. Smith of the Royal Aircraft Establishment introduced discussion $B$. After indicating the variety of situations in which free bounderies occur (such as at the surfaces of oceans, or of air bubbles rising through water or of the oil in journal bearings, in the design of wing shapes for a given pressure distribution, at the trailing vortex sheet behind a wing, at shock waves in locally supersonic flow, and at the surface of a sail distorted by wind forces), he drew a distinction between those problems which could be transformed into or approximated by a fixed boundary problem before numerical treatment and those which could not. He then described briefly a number of proper free-boundary problems and discussed in detail one in particular which had recently been solved successfully, namely, the determination of the strength and shape of spiral vortex sheets in a model of a flow with separation from a highly swept leading edge. In group $C$ the discussion on "Numerical Analysis" was continued; more detailed consideration 
was given to the treatment of singularities, and a general debate ensued on the kind of problems that numerical analysts ought to be examining.

The final session on the morning of September 29 was devoted largely to what must be the most challenging problem to fluid dynamicists, namely, the solution of the full Navier-Stokes equations. In the first lecture, Dr. S. C. R. Dennis of the University of Sheffield surveyed the progress to date in the field of steady flow, and discussed in considerable detail the difficulties that arise in tackling the classical external problem of two-dimensional flow past a circular cylinder. In particular, he considered suggestions that might overcome the major difficulty of the flow in the wake, which is especially troublesome at higher Reynolds numbers.

In the next lecture, on "Unsteady Flow", Dr. J. E. Fromm of the Los Alamos Scientific Laboratory demonstrated the feasibility of using a large digital computer to simulate the complex asymmetric fluid motions which really do occur in practical flow régimes, where the steady flow is unstable. He first gave a description of a finite difference technique for obtaining solutions of the twodimensional unsteady Navier-Stokes equations which had been developed with due regard for stability and conservation propertios. He then showed a series of impressive ciné films of the computer output for several flow problems. In order to make best use of the finite computer storage, only restricted flow fields were considered, namely, those between parallel plates. In the first problem the plates were moved so as to accelerate the fluid past a rectangular body; in the second the same configuration was considered, but the uncoupled temperature equation was solved as well, so as to simulate forced heat convection from the body. In the third problem, the Benard problem of thermal convection between fixed plates was considered; here, of course, the coupling between the temperature and momentum equations had to be taken into account. The filmed computer output showed the development in time of the streak-line patterns, the general features of which resembled the corresponding patterns produced in cxperiments to a remarkable degree. Shown also were the changing vorticity line patterns (or for the convection problems isotherm patterns). It should bo noted that if the data given were exactly symmetric, the symmetry was preserved in the solutions. The asymmetry had to be stimulated by introducing small perturbations; these were damped out for small Reynolds numbers, but amplified into typical eddying motions for larger Reynolds numbers. In the discussion group $A$ that followed (chaired by Prof. I. Proudman, University of Essex), it was pointed out that external flow problems were substantially more difficult to deal with numerically than internal ones, and Dr. Dennis suggested that a combination with analytical treatment of the far ficld might be the answer; howover, it would be very interesting to see Dr. Fromm's method applied directly to external flow problems. Another restriction that had been imposed because of limited storage capacity was a periodic boundary condition in the general flow direction; it would be of considerable interest to remove this so that any ultimate quasisteady patterns for large times could be studied.
The other two discussion groups on this last morning were: $B$, "Internal Aerodynamics" (chairman, Prof. J. H. Horlock, University of Liverpool) and $C$, "Turbulent Boundary-layers" (chairman, Prof. A. D. Young, Queen Mary College). Mr. R. Hetherington of Rolls-Royce, Ltd., gave an introductory talk in discussion group $B$, in which he discussed the two main two-dimensional problems that were used to model the essentially threedimensional process of flow through the complex of rotating and stationary blades that comprise a turbomachine. These are concerned mainly with eurved axial flow and cascade flow, respectively. Presently available methods wore briefly described and the extent to which computers were being used was surveyed. Although new methods were clearly needed to deal with the non-linear compressible and viscous effects, it was concluded that much could still be gained by developing existing methods with the aid of the modern computer.

The subject of turbulent boundary layers is, of course, of the utmost practical importance, but, up to the present, methods for calculating them have been developed on a purely empirical basis. Discussion group $C$ did, however, indicate that some substantial progress towards removing the empiricism from the direct relationship between shear stress and mean velocity profile to a less critical level is at last being made through analysis of the turbulent energy equation. This method leads (in two-dimensional flow) to a third-order hyperbolic system of partial differential equations, for which a characteristics method has been devised for solution on the computer. The computer can also be used to develop the traditional approach by exploring quickly and accurately the consequences of the various empirical assumptions regarding the relationship between shear stress and mean velocity profile. Here the differential equations are of similar type to the laminar boundary-layer equations, so with appropriate modifications the numerical techniques developed for the latter may be carried over.

The attention of the Computer Panel had recently been brought to work done at the National Physical Laboratory on the optimization of hull form parameters based on a statistical analysis of results from model tests of trawlers. The possibility of applying similar techniques to aircraft was thought worthy of investigation, so an additional discussion group was arranged to consider this after lunch on the last day. Mr. J. G. Hayes of the National Physical Laboratory described the technique in an introductory talk based on his paper on "Optimum Hull Form Parameters" read at the symposium on "Numerical Methods Applied to Shipbuilding" held at Bergen in 1963. Mr. D. J. Doust of the National Physical Laboratory added details of the significant improvements obtained in trawler design, and a short discussion followed under the chairmanship of Mr. J. G. L. Michel (National Physical Laboratory).

No proccedings are being published, but some copies of the programme and abstracts are still available and may be obtained from Mr. P. G. Williams, Mathematies Division, National Physical Laboratory, Teddington, Middlesex, under reference $M a .8 / 35 / 02$.

P. G. Williams

\section{BIOLOGICAL SCIENCES IN THE FUTURE UNIVERSITY OF BATH}

$\mathrm{O}^{\mathrm{N}}$ October 14, 1965, the first and preliminary-phase building of the future University of Bath was officially opened by the Mayor of Bath. Designed by the University architocts, Robert Matthew, Johnson-Marshall and Partners, this building occupies a corner of the 197acre site set aside by the City of Bath for the development of the new University. Constructed on the C.I.A.S.P. system, the structure was virtually completed in less than ten months, between the turning of the first sod in September 1964 to the handing over by the contractors in July 1965.

The two-storey structure forms a quadrangle, surrounding a central paved courtyard, the inner sides consisting mainly of staff offices and workrooms and the outer sides containing teaching laboratories, lecture and seminar rooms. Included in the specialist accommodation are 